\title{
SISTEMA DE INFORMAÇÃO COMO INSTRUMENTO DE GESTÃO DA QUALIDADE AMBIENTAL
}

\author{
Patricia Helen Lima \\ Mestre em Projeto Sustentável pela FAUUSP \\ Coordenadora da Seção de Informação e Qualidade Ambiental da Prefeitura de SBC \\ E-mail: patricia.helen.lima@hotmail.com
}

\begin{abstract}
Resumo
Este trabalho discute mecanismos de formulação e gestão de políticas públicas, sobretudo no nível local, abrangendo seus conteúdos temáticos (política social, ambiental e econômica), procurando entender sua evolução e seus resultados em termos da participação popular, dos interesses ambientais, econômicos e globais, apresentando alternativas que possam atender as necessidades contemporâneas em crescente mudança, numa sociedade em transição cultural.
\end{abstract}

Para interferir diretamente nesse processo, procuramos apresentar as dificuldades e limites da atual prática, e apresentar caminhos para se construir propostas articuladas de políticas de desenvolvimento integrado, sistematizado e sustentável.

Palavras-chaves: Qualidade Ambiental, Sistema de Informação, Políticas Públicas, Meio Ambiente, Planejamento Ambiental. 


\title{
INFORMATION SYSTEM AS AN INSTRUMENT OF ENVIRONMENTAL QUALITY MANAGEMENT
}

\begin{abstract}
This work discusses the mechanisms of creation and management of public policies, above all on a local level, covering its thematic contents (social, environmental and economic policies), trying to understand its evolution and its results in terms of popular participation, of environmental, economic and global interests, presenting alternatives that may attend to the contemporary necessities in growing changes, in a society in cultural transiton.
\end{abstract}

To interfere directly in this process, we tried to present the dificulties and limits of the current practice and present paths to build articulated proposals of integrated, systemic and sustainable development policies,

Keywords: Environmental quality, information system, public policies, Environment, Environmental planning.

\section{POLÍTICAS PÚBLICAS}

Políticas públicas são diretrizes de ação do poder público, procedimentos que norteiam suas relações com a sociedade. São, nesse caso, políticas formuladas em leis, projetos e programas, que normalmente envolvem recursos públicos. A esfera das políticas públicas também possui uma dimensão política, que envolve a distribuição de poder, o papel do conflito social nos processos de decisão, a repartição dos custos e benefícios sociais, evidenciando que nem sempre há compatibilidade entre as intervenções e as ações desenvolvidas.

A responsabilidade e encargos atribuídos ao Município são definidos na Constituição Federal e detalhados na Lei Orgânica. O município tem ampla autonomia para definir suas políticas e aplicar seus recursos. Nas áreas tradicionalmente objeto de políticas públicas, como assistência social, meio ambiente, habitação, saneamento, abastecimento, educação, saúde, o município tem competência comum com a União e o 
Estado, a ser exercida com a cooperação dessas esferas de poder, pela transferência de recursos, ou pela cooperação técnica.

Por ser Política pública, seu processo de elaboração é submetido ao debate público, o que a diferencia das Políticas governamentais, embora sejam estatais. Como o poder é uma relação social que envolve vários atores com interesses diferenciados e até contraditórios, há a necessidade de mediações sociais e institucionais, para que se possa obter um mínimo de consenso e, assim, as políticas públicas possam ser legitimadas e obter eficácia (TEIXEIRA, 2002).

As políticas urbanas iniciadas no Estatuto das Cidades e nos Fóruns Ambientais Globais abriram caminhos para mudanças significativas na função social, seguido de parâmetros para nortear a atividade produtiva dentro de um ambiente sustentável, englobando diferentes lógicas, que buscam um entendimento e que estabelecem relações que remontam às questões da sustentabilidade. Analisar tais questões no espaço urbano e seus impactos sobre os ecossistemas acarreta na revisão do processo das políticas públicas, que irá compor o projeto urbanístico no cumprimento de seu objetivo final (LIMA, 2009).

A condição na qual a ideologia sobre as questões ambientais e sociais se produz em nossa época -e que abrem possibilidades novas- encontra barreiras no mundo da economia global, onde as idéias se "desligam" da sua correspondência de origem, determinando a formação social e decorre daí um entendimento apenas parcial da realidade, nem sempre atrelado às culturas locais.

A globalização, um fenômeno que está predominado em todo mundo se manifesta de forma excludente e gera vários tipos de violência, causando danos econômicossociais e ambientais. Vale salientar que a pressão da globalização com força mercadológica cria a necessidade do governo buscar alternativas novas do contato direto com o cidadão superando o ortodoxo de fazer política. De igual maneira, a cidadania conscientemente organizada necessita criar mecanismo de contato e controle de políticas estatais, democratizando-as. Isso demanda novos experimentos de participação política direta de maior número possível de cidadãos. Assim, um dos maiores desafio da globalização é a discussão profunda e ampla a cerca de uma política da condição social humana global (CRUZ, 2009). 
Partindo da observação deste contexto de relações globalizadas, da hegemonia do capital aliado às questões sociais urgentes, é possível um exercício de análise das transformações ocorridas, onde se percebe que os esforços para a verdadeira compreensão dos novos conceitos têm sido depositados em ações para soluções conjuntas, para não corrermos o risco de sermos engolidos pela banalidade do contexto atual.

A criação de estruturas adequadas para a realização de um mecanismo comum, que troque as experiências de cada setor pela atuação que propicie poderes decisórios amplos, com múltiplas competências, com instrumentos que permitam ultrapassar obstáculos e que dêem segurança e compreensão necessárias é o caminho que entendemos possível para novas ações e que permitirão a transparência das informações para um meso nível de conhecimento.

\section{MEIO AMBIENTE NO PROCESSO DE GLOBALIZAÇÃO}

A expansão das forças globais sobre o espaço, a sociedade e as ações locais trouxe reflexões sobre a lógica que pauta este caminho. A intervenção do setor financeiro na lógica do espaço urbano e rural e na sua produção mostrou que as lógicas coexistem e se inter-relacionam, porém, quando incluída a lógica ambiental, nos deparamos com novos desafios.

Com o objetivo de explorar diferentes dimensões, escalas e relações, buscamos para exemplificar o conceito atual de área urbana e rural. O mundo rural secular opõe-se claramente ao mundo urbano, em suas funções, atividades, grupos sociais e paisagens. "Nos anos 80 assistiu-se uma nova realidade: o mundo rural não agrícola. Esta perspectiva introduziu elementos novos no modo de encarar os mundos rural e urbano, em si e na forma como se relacionam" (RÊGO FILHO, 2007). As decisões sobre as questões agrícolas tomadas no urbano e a submissão da ideologia dos padrões rural ao urbano, marcou uma visão de dominação urbana.

A idéia do mundo rural não agrícola trouxe em si transformações sociais. A ausência de movimentos significativos que apóiem os desenvolvimentos locais, a valorização simbólica atribuída ao mundo rural e a força do mercado alteraram definitivamente as relações entre urbano e rural.

Os aspectos hipervalorizados da conservação e proteção da natureza, a mercantiliza- 
ção das paisagens transformou o mundo rural, crescentemente reduzido, em espaços multifuncionais ou parques naturais sem expressão significativa. Com o crescente aumento da população urbana e a diminuição na qualidade da vida destes, surge o papel cada vez mais contrastante entre a imagem do rural buscado pela população urbana como próximo da natureza e a fuga da vida urbana. O rural de hoje, entendido neste contexto, não traduz o rural do passado, ou seja, a relação da sociedade rural com o espaço e seu registro local, no conjunto social. O sistema de valores da população rural de antes é substituído pelo individualismo que transformou o homem e a terra em mercadoria.

Enfrentamos agora novas questões sobre limites do urbano e do rural, que se encontraram fisicamente, com a extensão do tecido urbano. Nesta nova relação urbano-rural, é importante frisar, que uma nova relação urbano-rural terá que ser desenvolvida com um novo olhar sobre os espaços, de forma sinérgica em suas relações.

Estas relações pressupõem garantir o funcionamento de processos ecológicos básicos, como medida de preservação de ecossistemas. Significa garantir oferta pública de mobilidade, cultura e aprendizado às populações. Significa garantir que políticas de ordenamento do território e preservação da natureza sejam complementares e resultem no desenvolvimento adequado às novas redes que se criam.

O custo ambiental se associará à sua diversidade natural e à complexidade da problemática social, o que representará grande potencial para o seu desenvolvimento, envolvimento e troca. A proximidade de indústrias com fontes de energia e matéria prima não mudará a geografia econômica, mas alterará seu papel diante do mercado consumidor. A figura de rede substituirá a da Linha de produção (RÊGO FILHO, 2007).

Este é o estágio atual do processo de globalização, onde se tornam indispensáveis a interação e a consideração entre os níveis local, regional, nacional e global, o que significa sobrepor diferentes estruturas que comportam complexidades desiguais anteriores, como uma ordem próxima (de vizinhança) e uma ordem distante (da sociedade como um todo), que regem a produção e o consumo, da escala global.

A revisão do tamanho populacional dos municípios, sua densidade demográfica e sua localização serão obrigatórias tanto em conceitos como em normas legais, para a verdadeira compreensão da nova situação. As microrregiões são essenciais para a caracterização dos ecossistemas, ainda que artificializada pela ação urbana e nesse 
sentido, o campo não poderá ser concebido apenas como complementar a cidade e paisagem a ser consumida, mas como estruturador de um novo espaço, que contribua na valorização e reconhecimento dos seus saberes e potenciais locais, sem a condição de subordinação, envolvendo reais culturas.

Nasce a idéia de novas geografias que serão identificadas com sua espacialidade e suas marcas. Esta espacialidade terá que desenvolver e comportar a participação dos atores locais que desenvolverão e produzirão influências particulares. A escala de ação definirá as interações espaciais e a informação se construirá no conjunto dos atores e da gestão da proteção ambiental. Este processo será capaz de direcionar ações que busquem a qualidade da informação e das intervenções.

\section{TECNOLOGIA DA INFORMAÇÃO E CONHECIMENTO}

É preciso recuperar temas que permitam a construção de um quadro de práticas urbanas e rurais e que considerem os processos históricos e naturais, que não iludam, mas que influenciem ações mais abrangentes e cautelosas, uma produção do espaço que seja condição e meio para o processo da construção do território, considerando a espacialidade do processo social como intrínseca à análise territorial (LIMA, 2009).

A tecnologia avançada possibilita uma leitura conjunta de fatores que envolvem informações de diferentes fontes e que analisadas no todo representam uma ferramenta de gestão em que diversos atores podem usufruir e produzir um novo espaço, sob novas condições de realização e que possuam a potência de transformar a prática sócio-espacial. O desafio é explorar o desenvolvimento tecnológico para um objetivo de tornar as cidades sustentáveis.

SANTOS, equipara o desenvolvimento da história com o desenvolvimento das técnicas, dizendo que "A cada evolução técnica, uma nova etapa histórica se torna possível". (SANTOS, 2005). Em nossa época, o que é representativo do sistema de técnicas é a tecnologia da informação, do conhecimento e dos modelos digitais, permitindo todos os lugares convergirem os momentos e as ações desejadas, usufruindo das questões locais e globais e dos atores locais e globais.

Dispomos de um sistema de técnicas, com informações que se agrupam ao mesmo tempo e em qualquer lugar. Podemos ter uma visão detalhada da terra, observada por 
satélites, redes de infra-estrutura e rede social que as suportam, enfim, passamos a conhecer todos os lugares, funções, relações e produções e observá-los em sua evolução. Como síntese constitui-se em uma visão integrada, altamente elucidativa do conjunto interligado dos fatores físicos, bióticos e socioeconômicos responsáveis pela realidade e suas relações (Fig.1).

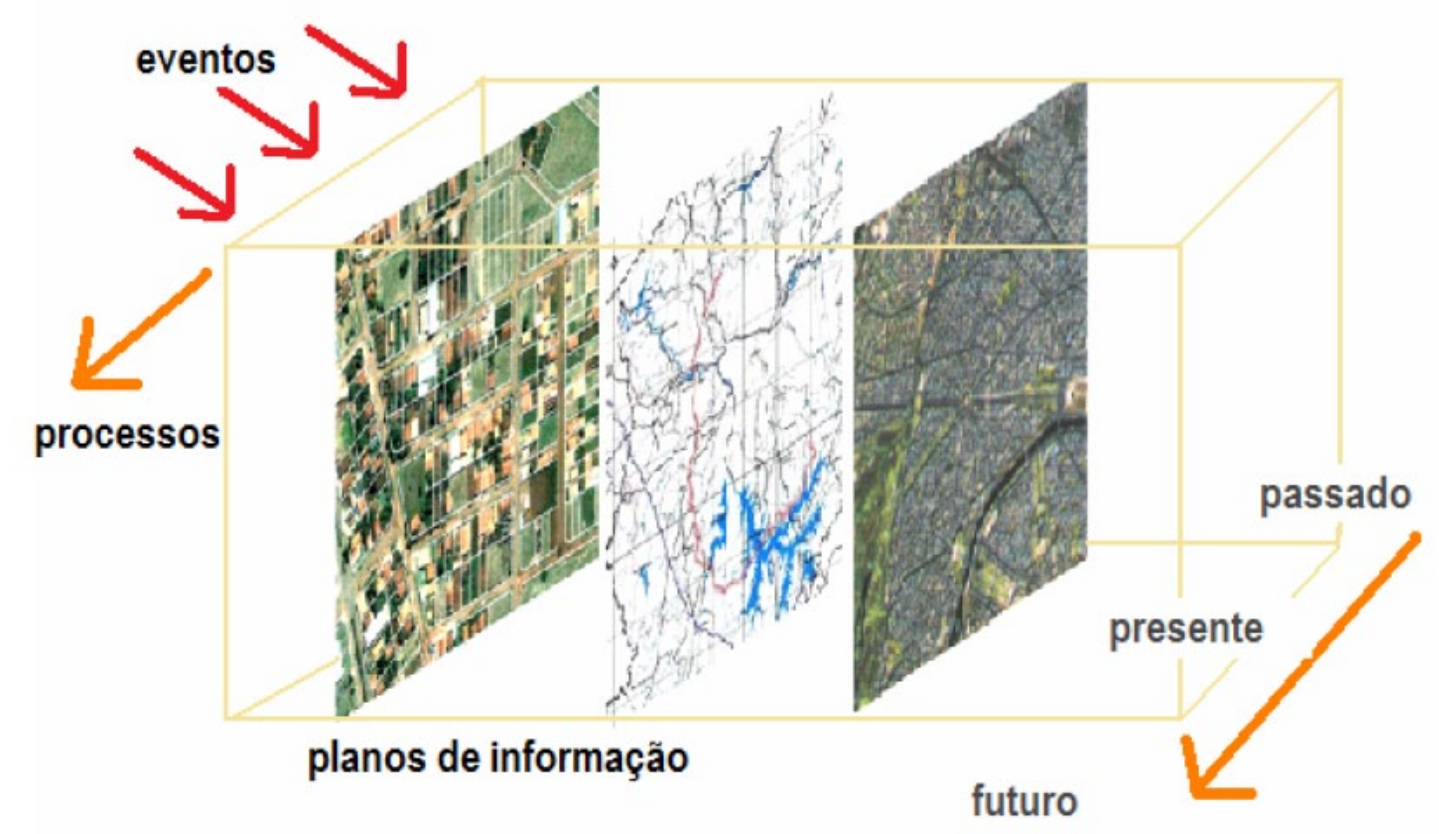

Fig.1 - sistemas geográficos de informação.

Muitas representações digitais do ambiente são extremamente úteis para o conjunto destas informações. São exemplos os mapeamentos temáticos e os bancos de dados. Estas representações podem ser integradas em uma estrutura que permita a investigação de relações entre as entidades físicas representadas e os impactos que as ações representam. Este cruzamento das informações cria modelos conceituais que representam diferentes facetas da realidade.

O sentido que têm todas estas ferramentas são a correta interpretação de tudo o que existe e que temos acesso e as possíveis intervenções no processo, para que sejam revistas as ações. Estamos buscando construir uma filosofia das técnicas e das ações, que seja uma forma de conhecimento amplo e concreto do mundo tomado como um todo e das particularidades dos lugares, que incluem condições físicas, naturais ou artificiais e condições políticas. Conhecer todo o processo das intervenções no território, suas relações e abrangência é uma necessidade de princípio para qualquer ação. Por exemplo, diversas atividades só são possíveis pela existência de recursos que 
não são produzidos ou extraídos em seu local e podem ser sentido em sua vizinhança. Nas cidades, os recursos naturais que utilizamos no dia-a-dia, o lixo que geramos, o solo que impermeabilizamos, o ar que poluímos chegam ao meio rural e podem não ser percebido na cidade, mas causam impacto.

O estudo das bacias hidrográficas, por exemplo, como uma unidade ambiental de análise é um caminho para uma investigação do meio, pois é possível analisar altitudes de terrenos ao longo da bacia, regular o fornecimento de água, preservar os solos férteis, ações humanas, a densidade demográfica e as razões econômicas, entender a drenagem, o fluxo dos cursos d'água, a distribuição das chuvas, o grau de impermeabilização, interpolando com o clima, estudar a funcionalidade do fornecimento, enfim, todos os componentes das bacias hidrográficas encontram-se interligados e os rios são os veículos dessa integração.

Devido a essa interligação natural, as bacias hidrográficas são excelentes unidades de planejamento e gerenciamento e constitui um sistema natural bem delimitado do espaço, composto por um conjunto de terras integradas e portanto mais facilmente interpretáveis.

O gerenciamento por Bacia hidrográfica exigirá um conhecimento que ultrapasse limites administrativos, mas que entenda os fluxos, que permita um diagnóstico da realidade, e mais ainda, permita requalificar áreas entre tantas situações que impossibilitam as decisões autônomas. Todas estas questões remetem à tecnologia atual na busca da qualificação do meio.

É necessário envolver diferentes setores permitindo um nível de entendimento entre atores para tomada de decisão cada vez mais transparente. Um sistema como parâmetro para induzir maiores mudanças, juntando-se a uma cidadania participativa para lidar com a especificidade dos problemas urbanos, criarão políticas públicas para resolver questões de ambientes específicos.

À medida que aumenta a conscientização da interdependência e à medida que o conhecimento e a informação mostram os problemas de forma cada vez mais clara e rápida, pode haver cooperação e apoio em diferentes estágios na busca de um novo equilíbrio entre sociedade, cidade e natureza. Esta é a força motriz que constrói uma sociedade sustentável. 


\section{QUALIDADE AMBIENTAL}

Em relação às questões que permeiam as informações relativas à qualidade ambiental, vale apresentar sucintamente a importância das informações sistematizadas no desenvolvimento de um planejamento ambiental, que representa um salto de qualidade na observação e interpretação do meio.

É comum surgirem questões sobre a lógica utilizada na seleção dos dados que são utilizados na análise do meio e que critérios definem este conjunto de dados para que sejam sistematizados e interpretados.

Todo planejamento que visa definir políticas requer conhecimento sobre os componentes que formam o espaço. $O$ dado é a base da informação, a medida, a quantidade ou o fato observado e pode ser apresentado na forma de números, descrições, caracteres ou mesmo símbolos. Este dado quando passa a ter uma interpretação se torna uma informação. Por sua vez, quando a informação é uma propriedade cuja variação deve alterar a interpretação do fenômeno que representa, sem lhe alterar a natureza, é chamada de parâmetro, que pode apresentar diversos valores, conforme a circunstância (Fig.2). Lembrando que para cada dado, informação, parâmetro ou variável obtido em um planejamento, deve-se reconhecer a temporalidade e o espaço de abrangência (SANTOS, 2004).

O importante é observar a ocorrência desses níveis, a relação que se pretende estabelecer entre eles, os dados que são representativos, comparáveis e de fácil interpretação, para construir uma base sólida de informações. Estas informações são apresentadas como indicadores, que têm a capacidade de descrever um estado ou uma resposta dos fenômenos que ocorrem no meio. A figura à seguir caracteriza o parâmetro como indicador.

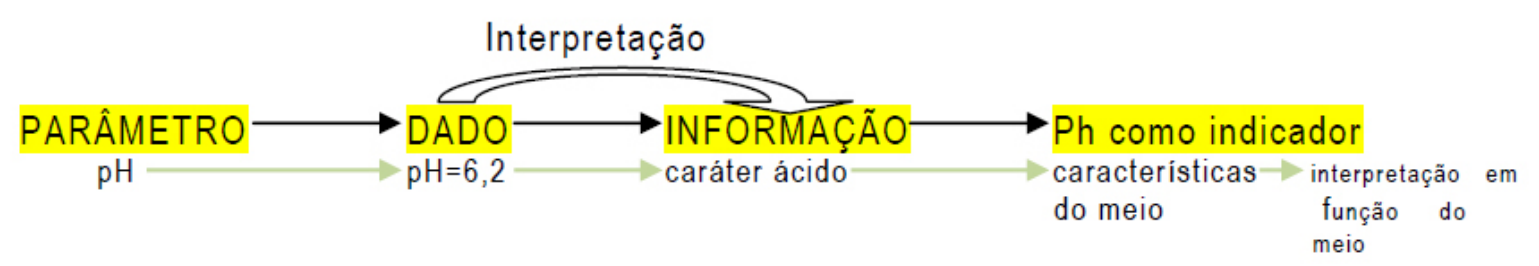

Fig. 2 Caracterização de parâmetro como indicador. Baseado em SANTOS, 2004.

Não existe consenso sobre qual o conjunto ideal de indicadores a ser adotado. Num planejamento ambiental o número de indicadores normalmente está associado à es- 
cala e espaço físico que se está trabalhando e para cada dimensão há indicadores específicos. Normalmente é comum priorizar os indicadores do meio natural e posteriormente os que expressam aspectos sociais, culturais e econômicos, ficando claro que a seleção dos dados populacionais e socioeconômicos está orientado segundo sua relação direta com os subsistemas ambientais naturais.

Importante é perceber que o agrupamento dos indicadores auxilia no processo de planejamento de diferentes maneiras, podendo expressar as condições de qualidade ou estado do meio, refletir as políticas setoriais, outro grupo pode refletir pressões ou impactos das atividades humanas sobre o meio, outro pelas relações sociais, e assim por diante.

A forma mais usual de organizar os indicadores, principalmente quando o planejamento fundamenta-se em princípios de desenvolvimento sustentável, é por meio da estrutura da OECD (Organization for Economic Co-Operation and Development), que adota três grupos de indicadores: estado, pressão e resposta.

\section{TEMÁTICAS E TEMAS}

Outra questão a ser a ser considerada em relação ao planejamento ambiental são seus múltiplos aspectos como um todo contínuo no espaço, que englobam dados ligados a diversas disciplinas. Na sistematização das diferentes disciplinas é necessário considerar dois níveis de informação: o das temáticas e o dos temas.

Cada tema é um núcleo próprio de dados, por exemplo: o clima, a geologia, a vegetação, o uso da terra, educação, entre outros, que podem ser subdivididos em subtemas e podem ser derivados, ou seja, abranger dois ou mais temas. Temática é um conjunto de temas, que quando associados permitem uma análise que é a síntese de uma fração particular do meio (SANTOS, 2004).

"Os planejadores precisam refletir que a compreensão sobre a complexidade do meio e a forma como se dá a integração entre seus diversos temas deve, primeiramente, passar pelo relacionamento entre os próprios elementos do grupo das múltiplas interações que os unem."(SANTOS, 2004) 
A partir das temáticas e temas é possível descrever e prever situações dentro da dimensão de análise estabelecida, sabendo que esses componentes não são isolados e apresentam padrões de distribuição no território estando relacionados numa rede de interações. Um caminho para representar esta integração é por meio da segmentação do espaço em unidades territoriais homogêneas, onde são analisados todos os temas agrupando os pontos com características comuns e denominando cada um segundo suas características.

Um caminho integrador dos temas que vem sendo utilizada no planejamento ambiental é a Ecologia da paisagem, porque ela permite aplicar procedimentos analíticos que conduzem à observação, sistematização e análise. A paisagem é observada como um conjunto de unidades naturais, alteradas por ação humana, que compõe um intrincado, heterogêneo e interativo mosaico, em que planejadores interpretam este mosaico e revelam as relações entre as unidades.

De acordo com Santos (2004), para o enfoque da paisagem são trabalhados três aspectos (Fig. 3):

- Estrutura - padrões e relações de distribuição entre elementos espaciais;

- Função - área heterogênea discutida em relação ao fluxo de espécies, energia e matéria entre esses elementos;

- Mudanças - alterações da estrutura e função do mosaico da paisagem através do tempo.
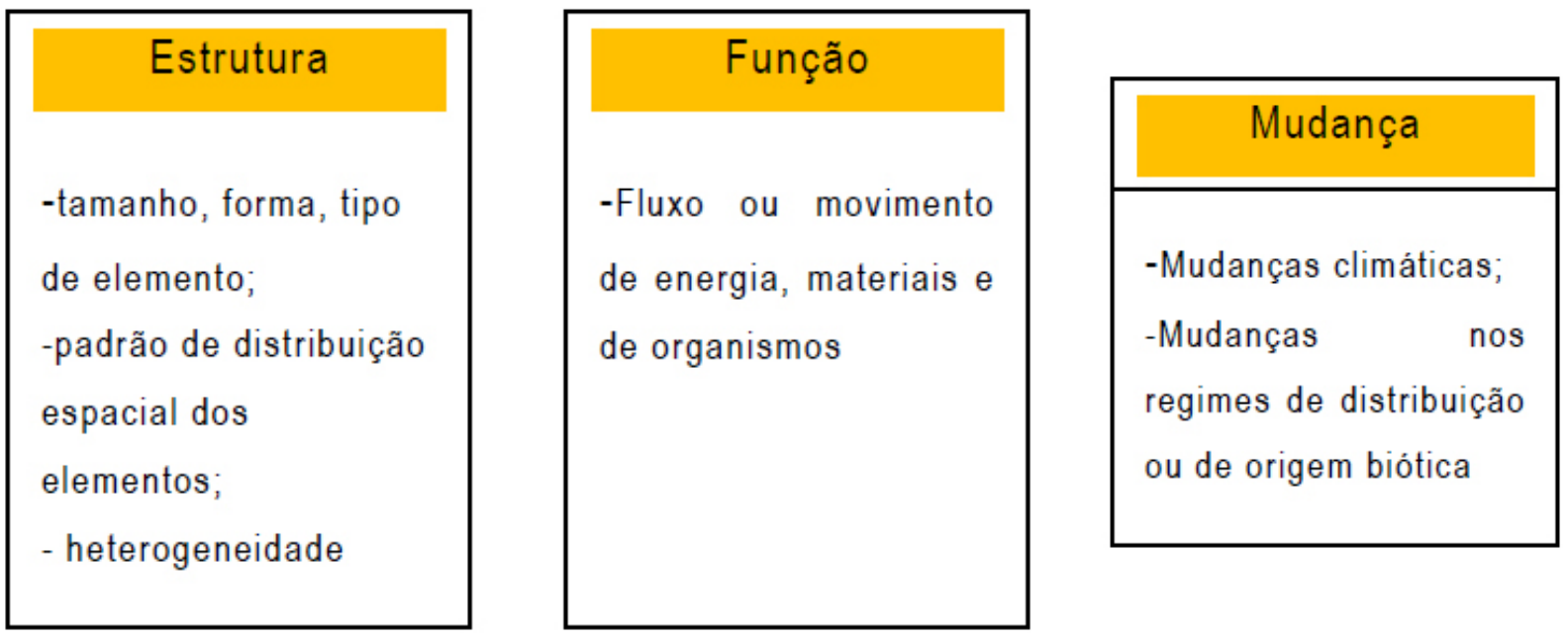

Fig. 3 - Estrutura, função e mudança na paisagem. Baseado em SANTOS, 2004

O olhar sobre a paisagem deve ser feito em dois eixos: no horizontal (definição de padrões mutuamente relacionados entre unidades) e vertical (define os atributos de 
cada estrato). Nos métodos tradicionais cada tema estuda um estrato e considera os demais como fatores de forma para seu próprio atributo. Considera, ainda, a heterogeneidade de uma área formada por todos os atributos como um objeto único de estudo (Fig. 4).

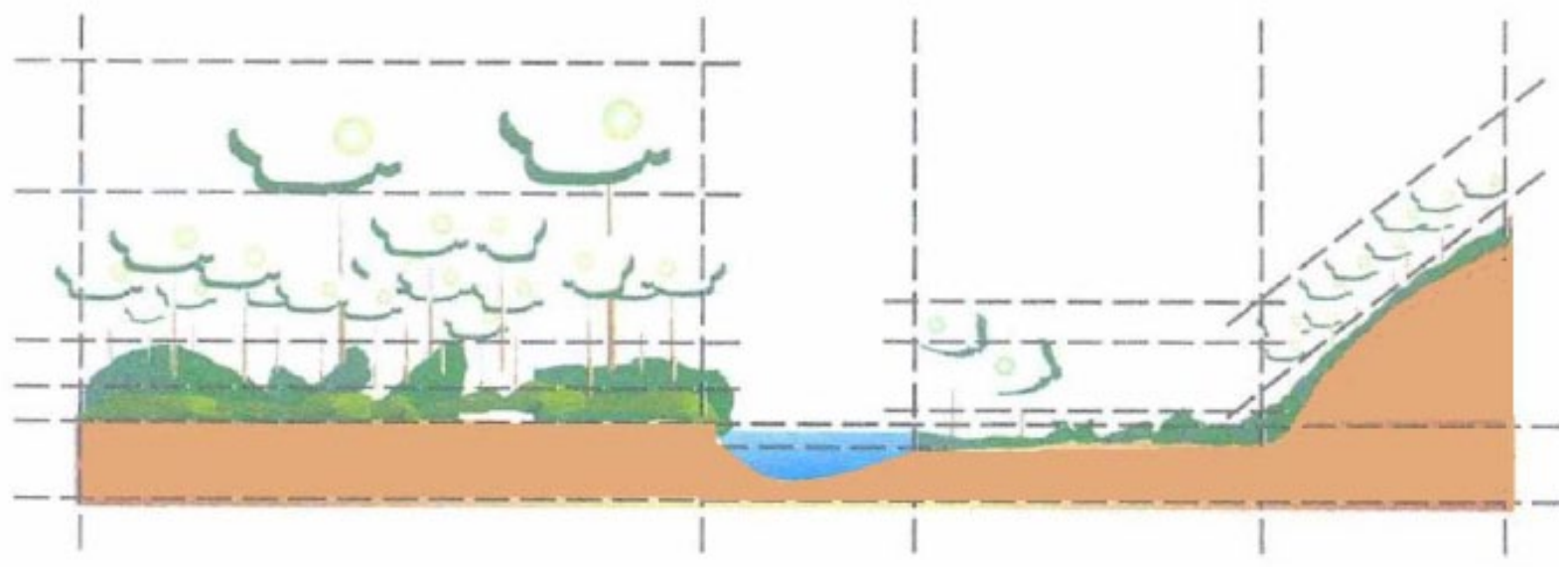

Fig. 4 - Observação do espaço, de acordo com o estudo da paisagem. SANTOS, 2004

O eixo vertical permite identificar os diferentes estratos cuja quantidade e composição depende da unidade, como florestas ou campos. O eixo horizontal permite identificar as diferentes unidades de paisagem.

Ainda sobre a perspectiva de análise sobre a função da paisagem, os planejadores indicam que a estrutura da paisagem reflete uma imagem imediata da distribuição da matéria pelos processos ecológicos num determinado tempo e que a observação por longos tempos apresentam a dinâmica do espaço. A estrutura é observada a partir de três elementos básicos: matriz, mancha e corredor (Fig. 5). 


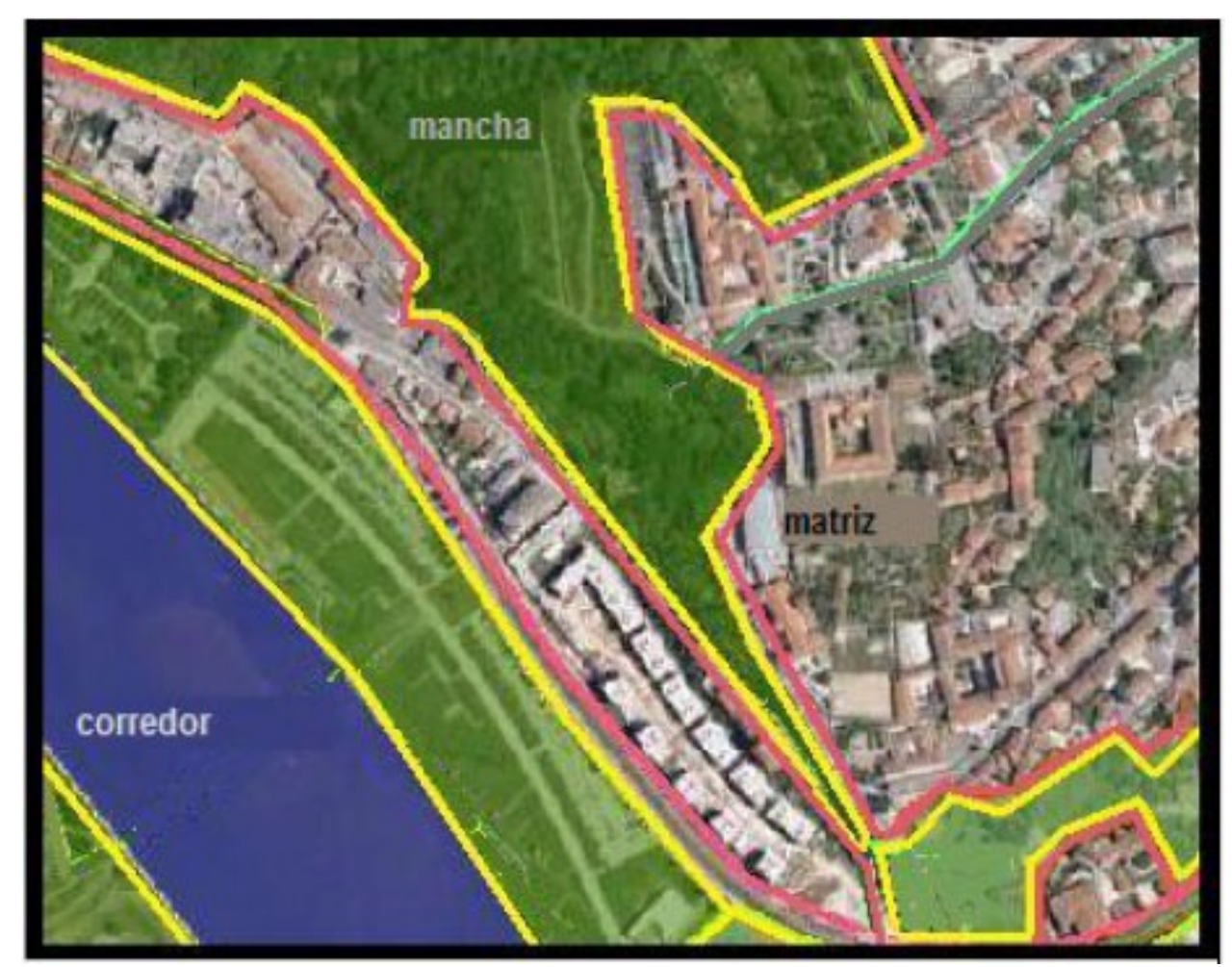

Fig. 5 - Representação dos elementos da paisagem.

A matriz controla a dinâmica da paisagem e é o elemento que tem o maior predomínio da área ocupada e com menor grau de fragmentação. As manchas são os elementos não lineares, de aparente homogeneidade e que interrompem a matriz. Os corredores são os elementos lineares, de aparente homogeneidade e distinguíveis da matriz. Podem ser classificados como corredores naturais, corredores de alteração ou distúrbio (estradas, linhas de energia), corredores de reabilitação (reflorestamento ciliar) e outros.

"A observação das interações entre a estrutura da paisagem (tamanho, forma, arranjo e conexão entre seus elementos) e seus processos ecológicos permite que vários fenômenos sejam averiguados, como: a capacidade do meio em recuperar-se e continuar em equilíbrio apesar de uma mudança; o tempo de sobrevivência de um sistema ou de algum de seus componentes; a resistência às mudanças, aos efeitos de barreira; as conseqüências das mudanças dos movimentos e transporte de agentes (organismos, água, ar) entre os elementos da paisagem; a medida da facilidade de ocorrência dos fluxos biológicos (conectividade); a permeabilidade da matriz; a evolução da fragmentação relacionada aos tipos de perturbação; 
os efeitos de borda dos fragmentos; os pontos de ligação (áreas de habitats dispersas), que facilitam os fluxos entre manchas, e a variação da diversidade na paisagem." SANTOS, 2004.

\begin{tabular}{|c|c|c|c|c|c|}
\hline & MATRIZ & MANCHAS & CORREDORES & CONECTIVIDADE & PERMEABILIDADE \\
\hline $\begin{array}{l}\text { natural } \\
\text { preservada }\end{array}$ & continua & $\begin{array}{l}\text { baixa densidade } \\
\text { de fragmentos }\end{array}$ & rede de drenagem & alta & alta \\
\hline agricola & geométrica & $\begin{array}{l}\text { média densidade } \\
\text { de fragmentos }\end{array}$ & $\begin{array}{l}\text { rede de drenagem } \\
\text { alterada e corredores } \\
\text { artificiais } \\
\text { (como trilhas) }\end{array}$ & baixa & baixa \\
\hline urbana & descontínua & $\begin{array}{l}\text { alta densidade } \\
\text { de fragmentos }\end{array}$ & $\begin{array}{l}\text { rede de drenagem } \\
\text { alterada e corredores } \\
\text { artificiais complexos } \\
\text { (como estradas) }\end{array}$ & baixa & baixa \\
\hline
\end{tabular}

Fig. 6 - Suposição de composição na paisagem em uma área com vegetação natural preservada, uma região essencialmente agrícola e uma área urbana. SANTOS, 2004

A interpretação pelo enfoque da ecologia da paisagem reflete muito bem a dinâmica das áreas estudadas e possibilita empregar medidas mais concretas de aproveitamento e conservação dos recursos da terra, apesar de ainda existir desacordo relacionado à noção de homogeneidade e heterogeneidade em função de diferentes questões, como escala adotada, percepção dos múltiplos processos existentes, formação do planejador, com estratégias próprias, considerando os diferentes campos de conhecimento, com princípios, conceitos e estratégias próprias, o que leva a procedimentos sob a ótica de diferentes profissionais.

\section{CONCLUSÃO}

As Considerações deste trabalho trazem reflexões de que o conhecimento deve absorver experiências e informações, que não podem ser confundidos com quantidade de dados isolados, caso contrário, não esclarecerão a leitura necessária à construção do território. Propiciar que os cidadãos se apropriem de suas localidades e que as políticas públicas contribuam com ações para educação do cidadão critico que possa exigir os seus direitos, que é co-responsável pela sua comunidade e sabe das necessidades da mesma é o caminho para uma boa gestão.

Partimos da hipótese de que a partir da relação entre circuitos financeiro, social e ambiental, adaptados ao conhecimento do espaço e das ações surgirá como resul- 
tado a realização das políticas públicas aplicada às localidades de forma consciente, participativa e qualitativa.

\section{REFERÊNCIAS BIBLIOGRÁFICAS}

CRUZ, Vicente Vagner. Repensando O Conceito De Políticas Públicas. Disponível em <http://www.artigonal.com/politica-artigos/repensando-o-conceito-de-politicas-publicas-756674.html> Acesso em Fev.2011.

RÊGO FILHO, Luiz de Morais e CARNEIRO, Auner Pereira. Relações entre o mundo rural e o mundo urbano: Evolução histórica, situação atual. Empresa de Pesquisa Agropecuária do Estado do Rio de Janeiro, Vinculada à Secretaria de Agricultura, Abastecimento e Pesca, 2007. Disponível em <http://200.255.4.232/Arquivos/Mestrado/GruposPesquisa/DesenvMunicipal/RelatoUrbanoRural.pdf> Acesso em Fev. 2011.

LIMA, Patricia Helen. Projeto Sustentável: Exigência para o Século XXI.

Percepção do projeto sustentável na produção imobiliária atual. Dissertação de Mestrado em Arquitetura e Urbanismo da Faculdade de Arquitetura e Urbanismo da Universidade de São Paulo, São Paulo, Nov. 2009.

SANTOS, Milton. Por uma outra globalização: do pensamento único à consciência universal. 12 ed. - Rio de Janeiro: Record, 2005.

SANTOS, Rozely Ferreira dos. Planejamento ambiental: teoria e prática. São Paulo: Oficina de Textos, 2004.

TEIXEIRA, Elenaldo Celso. O Papel das Políticas Públicas no Desenvolvimento Local e na Transformação da Realidade. 2002 - AATR-BA. Disponível em <http://www.dhnet. org.br/dados/cursos/aatr2/a_pdf/03_aatr_pp_papel.pdf> Acesso em Fev. 2011. 